\title{
Mirror Exposure and High-Fat Sauces Consumption in a University Cafeteria
}

\author{
Nicolas Guéguen, Virginie Charles-Sire \\ Université de Bretagne-Sud, Vannes, France. \\ Email: nicolas.gueguen@univ-ubs.fr, vc.sire@gmail.com \\ Received April 12 ${ }^{\text {th }}, 2011$; revised July $4^{\text {th }}, 2011$; accepted July $10^{\text {th }}, 2011$.
}

\begin{abstract}
A host of health problems are associated with consumption of refined sugar. Sauces such as ketchup, mayonnaise... contained higher level of refined sugar. Using behavioural influence techniques it could be possible to encourage consumer to reduce their consumption of refine sugar. In this study, the mirror exposure procedure was used in order to decrease students' sauces consumption in a university cafeteria. A mirror was stand or not in a self-service area with various sauces (mayonnaise, ketchup, mustard). People were unobtrusively observed and noticed which of the sauces was taken by each customer and the number of times the customer pressed on the sauce dispenser in order to obtain one dose of sauce. In the mirror exposure, the observers noted if the customer looked at the mirror when using the sauce dispenser. Results showed a decrease in consumption but only with individuals who look at them when using the saucedispensers. In a field setting, it was found that the mirror technique is an efficient method to decrease sauce consumption, and by extension, the consumption of refined sugar. The practical and the theoretical interest of this procedure are discussed.
\end{abstract}

Keywords: Mirror Exposure, Self-Perception, Behavioral Change, Diet, Sauces, Refined Sugar

\section{Introduction}

Many health problems are linked to excessive consumption of refined sugar, including diabetes, obesity, atherosclerosis, high blood pressure, heart attack stroke and some cancers [1]. It has been found that approximately $75 \%$ of the sugar we eat is hidden, added to processed and packaged foods. Sugar may occur in sauces such as tomato sauce, ketchup, brown sauce, mayonnaise, mustard...Thus given health problems associated with high level of sugar consumption, it would be interesting for health scientists and practitioners to use techniques that would lead individuals to reduce their own consumption of food products where hidden sugar is present.

The positive effect of mirror exposure on the improvement of behavioral symptoms associated with eating disorders had been found in several studies. This technique involves patients systematically observing themselves in a full-length mirror. Delinsky and Wilson [2] have found that using this technique with women with extreme weight and shape concerns led significantly to greater improvement in body checking, body image avoidance, and concern about weight and shape. With obese adolescents, it has been found that mirror exposure proved to be a powerful strategy to decrease anxiety and to increase body satisfaction [3]. It has also been found that among eating-disordered patients, the entrance levels of negative thoughts and feelings were lower at post mirror exposure compared to pre-BIT, whereas they remained stable in the control condition where no mirror exposure was used [4-6]. So, given the positive effect of the mirror exposure technique in order to increase individuals' concern about their weight and shape, we conducted an experiment in which a mirror was set or not behind different sauce dispensers. According to previous studies, we hypothesized that mirror presence compared to mirror absence would be associated with a decrease in sauce consumption.

\section{Methods}

Participants: the participants were 941 students (166 females and 775 males) aged between 18 and 22. They were unobtrusively observed in a university cafeteria when taking various sauces after just after leaving the self-service place where various items (starters, cold or warm dishes, desserts) had been proposed to them. 
Procedure: the experiment was conducted in a university cafeteria of the university of Bretagne-Sud located in the town of Lorient (with above 80,000 inhabitants) in the French West-Atlantic coast. For two weeks, six observational periods were defined to observe the students. The manipulation of the two experimental conditions was performed according to a random distribution between the 6 periods considered for the observation. The observation was done from $12 \mathrm{p} . \mathrm{m}$. to $1 \mathrm{a}$ a.m. when most of the students went into the cafeteria for lunch. During this period, approximately a mean of 683.6 students $(S D=54.99)$ used the self-service for their lunch. Given the fact that only a part of the students added sauce in their meals, 4102 participants were observed. In the mirror condition we found that $22.15 \%$ consumed sauces whereas they were $23.84 \%$ in the non mirror exposure condition. No difference was found in the two groups $\left(\chi^{2}(1, N=4102)=1.68, n s, r=.02\right)$ arguing that the two samples were the same when considering the ratio of people who consumed or not sauce. This non difference also attested that the mirror exposure was not sufficient to decrease the number of students who intended to consume some sauces.

The cafeteria consisted in a self-service restaurant which required the students to use a tray to put various items (one starter, one dish and two desserts or one dessert and one green salad) which were set on different displays. Customers used a tray rail to put their item on top of their tray and slid it along the different food areas. At the end of the tray rail, an employee was sat in order to check each student's and to collect his/her luncheon voucher. Two meters away from the end of the tray rail, there was a stand where various sauces were proposed in self-service for the students. It's important to note that the place and the configuration of the stand which proposed the sauces were strictly the same as usual. In the first line, 5 sauce machines were put on the stand ( 3 contained mayonnaise, one contained ketchup and the last one contained mustard). On the second line 2 sauce machines were presented (one with vinaigrette and the other with olive oil). According to the observational period a mirror was present or not behind these 2 lines of sauce dispensers (see Figure 1). The size of the mirror was 26 inches long and 34 wide. It was placed approximately 1.2 $\mathrm{m}$ in front of the person at a height of $1.2 \mathrm{~m}$ and presented with an angle of 2 degrees. By this way, most of the customers were able to see their face and the top of their chest. The measure of sauce consumption was done only with students who went to the table where the sauce machines were presented and who consumed only sauces presented in the first line (Mayonnaise, Ketchup or Mustard). Students who consumed only vinaigrette or olive oil were not included in the data analysis. Two observers stood in another area of the restaurant where it was possible for them to observe the sauce stand and students' behavior with a high discretion level. Both were instructed to notice which of the sauces was taken by each customer and the number of times the customer pressed on the sauce dispenser in order to obtain one dose of sauce. A high level of inter-coder reliability was found in this experiment, $r=1.00, p<0.001$; so, the mean of the two coders' counts was used as the dependent variable. The observers were also instructed to note if students in the mirror exposure condition, looked at the mirror when using the sauce dispenser (see Figure 2). Pre-experimental observation found that few students performed this behavior ( $<$ to $8 \%$ ). Thus, it was decided to split up the data in the mirror exposure condition according to the fact that students looked or did not look at the mirror when using the sauce dispensers. Again, a high level of inter-coder reliability was found for this behavior, $r=$ $0.99, p<0.001)$.

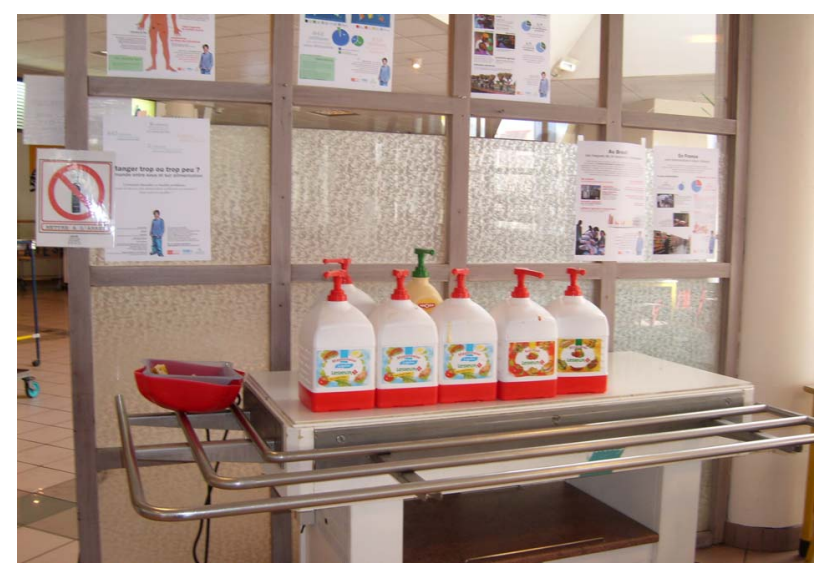

Figure 1. Experimental area with table and sauce dispensers.

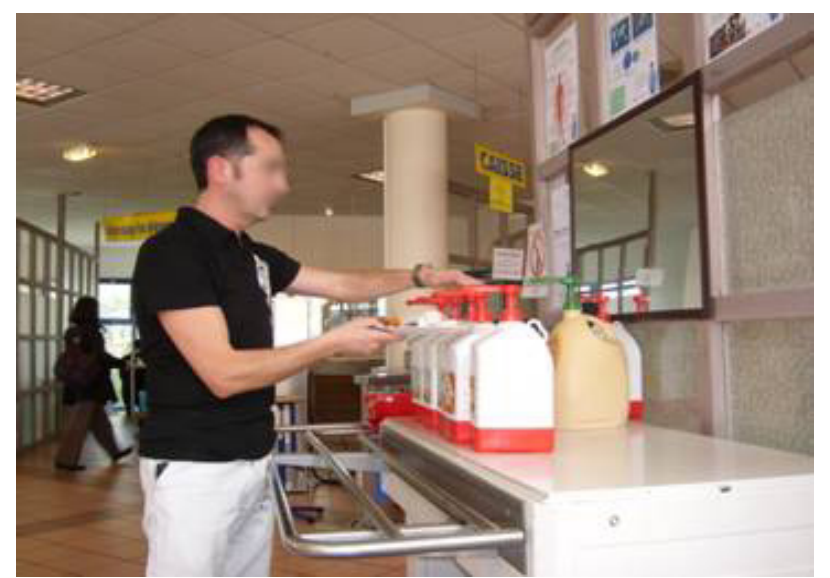

Figure 2. Experimental area in the mirror condition and with an individual looking at the mirror when using the sauce dispenser (the face was blurred to preserve the individual anonymity). 


\section{Results and Analysis}

The experiment focused on behavioural data, so, the single dependent variable measured here was the number of pressures performed by the participants to obtain their sauce. As some students consumed more than one sauce, a composite score adding the consumption of the three products was calculated for each student. The data obtained, according to the two experimental conditions and student's gender, are presented in Table 1.

A 2 (sex) $\times 2$ (experimental condition) analysis of variance (ANOVA) was used to analyze our data. A main effect of the gender of the customer was found on consumption $\left(\mathrm{F}(1,940)=32.09, p<.001 \eta^{2}=0.03\right)$ revealing that, overall the number of sauce pressures was lower with females (2.97) than with males (4.01). Neither main effect of the experiment condition $(F(1,940)=0.03$, $n s ; \eta^{2}=0.00$ ) nor the interaction between experimental condition and participant's gender $(F(1,940)=0.69$, ns; $\left.\eta^{2}=0.00\right)$ was statistically significant. Thus, the presence of the mirror was not associated with variation in the degree of sauce consumption compared to the condition where no mirror was present.

In order to distinguish participants who looked at the mirror and participants who did not, a second analysis was performed. Data of the two groups are presented in Table 2.

A 2 (sex) $\times 2$ (looking condition) analysis of variance (ANOVA) was used to analyze our data. A main effect of the looking condition was found $(\mathrm{F}(1,479)=5.87, p<$ $\left.0.02 \eta^{2}=0.01\right)$ revealing that the number of sauce pressures was lower with participants who looked at themselves in the mirror than with participants who did not engage in such behavior. Neither main effect of the participants' gender $\left(\mathrm{F}(1,479)=1.26, n s ; \eta^{2}=0.00\right)$ nor the interaction between looking condition and participants

Table 1. Means (standard deviation in brackets) of pressures on the sauce dispensers according to the mirror exposure and participants' gender.

\begin{tabular}{cc}
\hline Condition & Total number of pressures \\
\hline No mirror exposure & \\
Males & $4.09(2.31) \mathrm{N}=375$ \\
Female & $2.90(1.36) \mathrm{N}=87$ \\
Total & $3.86(2.21) \mathrm{N}=462$ \\
Mirror exposure & \\
Males & $3.93(2.19) \mathrm{N}=400$ \\
Females & $3.04(1.56) \mathrm{N}=79$ \\
Total & $3.78(2.12) \mathrm{N}=479$ \\
\hline
\end{tabular}

Table 2. Means (standard deviation in brackets) of pressures on the sauce dispensers in the mirror according to participants' look at the mirror and participants' gender.

\begin{tabular}{cc}
\hline Condition & Total number of pressures \\
\hline Look at the mirror & \\
Males & $2.57(1.22) \mathrm{N}=14$ \\
Female & $1.41(0.58) \mathrm{N}=11$ \\
Total & $2.50(0.98) \mathrm{N}=25$ \\
No look at the mirror & \\
Males & $3.98(2.20) \mathrm{N}=386$ \\
Females & $3.15(1.64) \mathrm{N}=68$ \\
Total & $3.85(2.15) \mathrm{N}=454$ \\
\hline
\end{tabular}

gender $\left(\mathrm{F}(1,479)=0.57, n s ; \eta^{2}=0.00\right)$ was statistically significant.

When comparing participants who looked at the mirror $(M=2.50, S D=0.98)$ and participants in the non mirror control condition $(M=3.86, S D=2.21)$ a significant difference was found $(t(485)=3.06, p<0.003, d=0.28)$ whereas there was no difference between this later group and the participants in the mirror condition who did not look at the mirror $(M=3.85, S D=2.15)$ : $(t(914)=0.07$, $n s, d=0.00)$. So, it seems that looking at the mirror is needed to affect the participant's behavior.

So, among the 25 participants for whom observers noticed that they had looked at the mirror, we found lower sauces consumption than among the participants for whom observers stated that they had not looked at the mirror and among the participants who were not exposed to the mirror. However, in order to prevent possible experimental artifact in which participants in the group who looked at the mirror were only participants who happened to be the smallest participants, further evaluations were made. We found that in this group the mean was equal to 2.5 beginning with 2 pressures for the smallest consumer and ending with 6 pressures for the biggest customer. In the group whose participants did not look at the mirror, 43 out of 454 had a number of pressures that was lower than 2 pressures. In the group not exposed to the mirror, 35 out of 462 had a number of pressures lower than 2. Thus, the sub-group who looked at the mirror seemed not to be composed only by the lowest customers. On the contrary, the lowest customers were presented in the group who did not look at the mirror.

\section{Discussion}

In this experiment using mirror exposure in order to decrease sauce consumption in a student cafeteria, we did not find an overall effect of the presence of the mirror on 
the number of pressures performed on the sauce dispenser.However, when considering participants in the mirror condition, those who actually looked at their reflection while using the sauce dispensers showed decreased sauce consumption compared to those participants who did not look at their reflection and those in the control (no mirror) condition. Accordingly, if the mirror is necessary to obtain a decrease in consumption, the psychological mechanism associated with this decrease may be related to the perception of the mirror. Indeed, the consciousness of the mirror is perhaps a condition to obtain an effect on the participants' behavior. The small size of the mirror used in our experiment may have contributed to a lack of awareness of the mirror which was sufficiently long and wide to permit to reflect the entire body size of one individual. In order to increase the level of the participants' consciousness of the mirror, it would be interesting for further study to use mirrors with higher probability to be noticed than the mirror used in our experiment.

Nonetheless, our results confirm that the "mirror technique" is appropriate in research that focuses on eating disorders. Recently Markey [7], showed that positive and inspiring messages written on bathroom mirrors in university dormitories (e.g. Our body is a vehicle for awakening. Treat it with care; Beauty comes as much from the mind as the eye.) can raise student awareness about the prevalence and severity of eating disorders and effecttively increase student and concerns". In another study [8], students expressed greater concern about eating disorders when they were previously exposed, under laboratory conditions, to their reflection. These recent studies combined with our results, demonstrate the methodological and applied interest of using the "mirror reflection" technique in the prevention of eating disorders.

These results had some methodological importance when comparing our method and the method used in previous studies that have tested the effect of mirror exposure on individuals' concern about their weight and shape. In these studies participants were often sat in front of a mirror from 5 to 50 minutes. In our experiment this was not the case, and only few seconds were necessary for the students to take their sauce. This short time and the procedure used seem to greatly reduce the level of participants' consciousness of the mirror presence. However, with people who looked at their reflection and thus were aware of the mirror presence, an effect was observed. Such results seem to show that, when considering behaviors and not attitudes as in the previous studies, using the technique of the mirror exposure does not imply that an individual is necessarily exposed to the mirror for a long time. With very short-time exposure a behavioral effect can be obtained.
From a theoretical point of view, the results of our study confirm that material objects associated with particular contexts can influence people's behavior. In this experiment, the mirror probably acted as a "material prime" that exerted automatic and unconscious effect on relevant choices and judgment [9]. Experimental studies in social psychology confirm that environmental cues have an influence on individual behavior. Berkowitz and LePage [10] found that in the presence of a weapon, participants in a laboratory study administered more electric shocks to a confederate than when there was no weapon. Feinberg [11] showed that in the presence of credit card cues, an individual is more likely to give money to charity. Research has also found that food consumption can be influenced by material objects present in the customer's environment, such as when visual cues related to the sea (a boat or a sailor figurine, a napkin with a picture of a boat and poetry related to the sea) decorate dining tables in a restaurant setting [12]. According to the Spreading Activation Theory [13], information in our environment (material objects, verbal information, odors...) is encoded into cognitive units that form a complex interconnected network. Triggering a cognitive unit not only retrieves information stored in that unit, but also potentially activates all other cognitive units that are semantically connected to the initially triggered cognitive unit. The simple exposure to a visual cue is sufficient to activate the network where information about the object or picture is encoded. Individuals can retrieve not only the concept associated with a visual cue (e.g., boat, sailor), but also further cognitive units that become available. In the study reported here, people exposed to a reflection of their head and shoulders are likely to have encoded information associated with self-concept (physical components of their face, subjective evaluation of their own apparent health...). Such encoding may have activated further concepts associated with their concerns about health, food control, physical attract- tiveness, self-image to display for others. In turn, these concerns led people to act in keeping with such concepts. This seems to be the reason why students who actually observed their reflection took less sauce.

\section{REFERENCES}

[1] M. Nestle, "Food Politics: How the Food Industry Influences Nutrition and Health," University of California Press, Los-Angeles, 2007.

[2] S. S. Delinsky and G. T. Wilson, "Mirror Exposure for the Treatment of Body Image Disturbance," International Journal of Eating Disorders, Vol. 39, No. 1, 2006, pp. 108-116. doi:10.1002/eat.20207

[3] A. Jansen, D. Bollen, B. Tuschen-Caffier, A. Roefs, A. Tanghe and C. Braet, "Mirror Exposure Reduces Body 
Dissatisfaction and Anxiety in Obese Adolescents: A Pilot Study,” Appetite, Vol. 51, No. 2, 2008, pp. 214-217. doi:10.1016/j.appet.2008.01.011

[4] S. Vocks, A. Wächter, M. Wucherer and J. Kosfelder, "Look at Yourself: Can Body Image Therapy Affect the Cognitive and Emotional Response to Seeing Oneself in the Mirror in Eating Disorders?” European Eating Disorders Review, Vol. 16, No. 2, 2008, pp. 147-154. doi:10.1002/erv.825

[5] S. Hofmann and N. Heinrichs, "Differential Effect of Mirror Manipulation on Self-Perception in Social Phobia Subtypes," Cognitive Therapy and Research, Vol. 27, No. 1, 2003, pp. 131-142. doi:10.1023/A:1023507624356

[6] S. Vocks, J. Kosfelder, M. Wucherer and A. Wächter, "Does Habitual Body Avoidance and Checking Behavior Influence the Decrease of Negative Emotions during Body Exposure in Eating Disorders?” Psychotherapy Research, Vol. 18, No. 3, 2007, pp. 412-419.

[7] C. N. Markey, "Social Influences on Body Image and Dieting Behaviors," Presentation for the Psychology Department at Haverford College, 2004.

[8] J. A. Bargh, "The Four Horsemen of Automaticity: Awareness, Intention, Efficiency, and Control in Social Cognition,” In: R. S. Wyer Jr. and T. K Srull, Eds., Handbook of Social Cognition, Erlbaum, Mahwah, 1994, pp. 1-40.

[9] N. Guéguen, A. S. Delcroix, F. Doudard, L. Dubern, M. Dulin, O. Faye, C. Grau, H. Kerzerho, A. Le Bourvellec, J. Le Caignec and A. Le Guen, “Technique de 'l'Exposition au Miroir' et Variation Automatique du Comportement Alimentaire: Une Illustration dans un Restaurant Universitaire,” Les Cahiers de Nutrition et de Diététique, Vol. 45, No 1, 2010, pp. 37-43.

[10] L. Berkowitz and A. LePage, "Weapons as AggressionEliciting Stimuli,” Journal of Personality and Social Psychology, Vol. 7, No. 2, 1967, pp. 202-207. doi:10.1037/h0025008

[11] R. A. Feinberg, "Credit Cards as Spending Facilitating Stimuli: A Conditioning Interpretation,” Journal of Consumer Research, Vol. 13, No. 3, 1986, pp. 348-356. doi:10.1086/209074

[12] C. Jacob, N, Guéguen and G. Boulbry, "Presence of Various Figurines on a Restaurant Table and Consumer Choice: Evidence for an Associative Link," Journal of Foodservice Business Research, Vol. 14, No. 1, 2011, pp. 47-52. doi:10.1080/15378020.2011.548221

[13] J. R. Anderson, "A Spreading Activation Theory of Memory," Journal of Verbal Learning and Verbal Behavior, Vol. 22, No. 3, 1983, pp. 261-295. doi:10.1016/S0022-5371(83)90201-3 